\title{
Experimental study on a resorption system for power and refrigeration cogeneration
}

\author{
L. Jiang, L.W. Wang*, C.Z. Liu, R.Z. Wang \\ Institute of Refrigeration and Cryogenics, Key Laboratory of Power Machinery and Engineering of \\ Ministry of Education, Shanghai Jiao Tong University, Shanghai, 200240, China
}

\begin{abstract}
Energy conversion technologies, especially for power generation and refrigeration technologies driven by the low temperature heat, are gathering the momentum recently. This paper presents a novel resorption system for electricity and refrigeration cogeneration. Compared with adsorption refrigeration system, resorption refrigeration is characterized as safety and simple structure since there is no ammonia liquid in the system. The cogeneration system is mainly composed of three high temperature salt (HTS) unit beds; three low temperature salts (LTS) unit beds, one expander, three ammonia valves, two oil valves, four water valves and connection pipes. Chemical working pair of $\mathrm{MnCl}_{2}-\mathrm{CaCl}_{2}-\mathrm{NH}_{3}$ is selected. Since scroll expander is suitable for small type power generation system, it is chosen for expansion process. $4.8 \mathrm{~kg} \mathrm{MnCl}_{2}$ and $3.9 \mathrm{~kg} \mathrm{CaCl}_{2}$ impregnated in expanded natural graphite treated with sulfuric acid (ENG-TSA) are filled in the cogeneration system. Experimental results show that maximum cooling power $2.98 \mathrm{~kW}$ is able to be obtained while maximum shaft power is about $253 \mathrm{~W}$ with $82.3 \mathrm{~W}$ average value. The cogeneration system can be utilized for the heat source temperature lower than $170^{\circ} \mathrm{C}$. Total energy efficiency increases from 0.293 to 0.417 then decreases to 0.407 while exergy efficiency increases from 0.12 to 0.16 .
\end{abstract}

\section{Keywords}

Resorption; Refrigeration; Scroll expander; Power

\footnotetext{
* Corresponding author. Tel.: +86-21-34208038; Fax: + 86-21-34206814

Email: 1wwang@ sjtu.edu.cn (L.W. Wang)
} 


\section{Nomenclature}

c

Specific heat $\left(\mathrm{kJ} /\left(\mathrm{kg} .{ }^{\circ} \mathrm{C}\right)\right)$

COP

Coefficient of performance

E

Exergy $(\mathrm{kJ} / \mathrm{kg})$

HTS

High temperature salt

$h$

Enthalpy $(\mathrm{kJ} / \mathrm{kg})$

LTS

Low temperature salt

$m$

Mass flow rate $(\mathrm{kg} / \mathrm{s})$

$P$

Pressure $(\mathrm{Pa})$

$Q$

Heating power $(\mathrm{kW})$

$\mathrm{R}$

Gas constant $(\mathrm{J} /(\mathrm{mol} . \mathrm{K}))$

$S C P$

Specific cooling power $(\mathrm{W} / \mathrm{K})$

Time (s)

Temperature $(\mathrm{K})$

Power output of expander (W)

Adsorption quantities $(\mathrm{kg} / \mathrm{kg}$ )

\section{Greek letters}

$\Delta H$

$\Delta x$

$\rho$

\section{Subscripts}

ave

chill

HTS

heat

in

$\mathrm{NH}_{3}$
Enthalpy of HTS adsorbent

Adsorption quantity variation $(\mathrm{kg} / \mathrm{kg})$

Density of ammonia $\left(\mathrm{kg} / \mathrm{m}^{3}\right)$

Avarage

Chilled water

High temperature salt

Heating

Inlet

Ammonia 
Oil

Reaction

Refrigeration

Resorption

Outlet

Total

Glycol water solution

\section{Introduction}

In recent years, utilization of low grade heat has drawn an increasing number of attentions due to high energy consumption and severe environmental pollution. Power generation and refrigeration are two major hot topics by utilizing low grade heat $[1,2]$. Power, characterized as high-grade energy , exists extensive and high demanding[3]. For high temperature heat source, Rankine cycle is widely applied in thermal power plants by using fossil, nuclear, solar and biomass energy source. Nonetheless, its endothermic process for water evaporation cannot make use of the heat source with high efficiency. For middle and low temperature heat source, Kalina cycle and Organic Rankine cycle (ORC) are two methods for power generation driven by the low grade heat. For Kalina cycle it can fit the trend of heat source and compensate the deficiency of Rankine cycle [4], which proves to have great potential for heat recovering[5]. For ORC, due to energy consumption of pressure pump, energy efficiency is not as high as $10 \%$ in the real system [6]. To improve energy efficiency for utilizing the low grade heat, power generation and refrigeration are considered to be combined. One method is cascading power generation cycle with refrigeration cycle which can match different heat source temperature. Wang et al.[7] connected expander of ORC system with compressor of vapor compression refrigeration to realize power and refrigeration cogeneration. Results showed total energy efficiency could reach 0.66 . Mohanty et al. [8] cascaded ORC system with absorption chiller, and refrigeration power produced by the chiller was used to lower the condensing temperature of ORC to increase the power output as well as to improve the system efficiency. Wang et al.[9] established and analyzed solar powered cascading cogeneration cycle with ORC and adsorption technology. Results indicated that the total exergy efficiency was 0.56-0.74. Jiang et al.[10] investigated cascading cogeneration system of ORC and $\mathrm{CaCl}_{2} / \mathrm{BaCl}_{2}$ two-stage adsorption freezer. The cascading cycle improved the exergy efficiency for the 
heat utilization to $20.4 \%-29.1 \%$. Comparably, the other method is combining power generation with refrigeration in one thermodynamic cycle.Combining absorption refrigeration and power generation has been investigated. One example was Goswami cycle, which was expected to improve energy and exergy efficiency by utilizing the working pair of ammonia and water[11]. However, the total efficiency was not high because Goswami cycle recovered cooling power of expanded cold gas through one procooler, which was sensible heat rather than latent heat[12].

Adsorption refrigeration is gathering the momentum since it is characterized as environmental benign and utilization of low grade heat[13]. Adsorption chiller has been investigated for many years and physical adsorption chiller has achieved industrialization in air conditioning application. Two-bed continuous silica gel-water adsorption refrigeration chiller has been widely utilized in a solar-powered cooling system in recent years. Luo et al.[14, 15] applied silica gel-water adsorption chiller into a solar-powered adsorption cooling system. Cooling capacity of this system was $3.06-4.18 \mathrm{~kW}$ while a daily solar cooling COP ranged from 0.1 to 0.13 . Based on adsorption refrigeration, some researchers has tried to add expander between the reactor and condenser for additional electricity. Bao et al. [16] investigated the chemisorption cooling and power cogeneration system driven by low grade heat. However, since the scroll expander was not suitable for adsorption system, electricity efficiency of the cogeneration system was not high. After that, Bao et al.[17] established the concerning model of scroll expander for analyzing the ideal operation performance for this adsorption-cogeneration system. Results showed that the cogeneration system was able to achieve $1000 \mathrm{~W}$ power output for optimal working condition. Nonetheless, there will be two main deficiencies if ammonia is used as working fluid for adsorption refrigerator. One is safety problem that may be caused by liquid ammonia in the system; The other is that performance of adsorption refrigeration will be greatly affected by the ambient cooling temperature. When cooling temperature is higher than $35-40^{\circ} \mathrm{C}$, refrigeration performance will decrease significantly. Actually, resorption refrigeration can match different reaction equilibrium temperatures when different alkali metal halides are employed [18]. Since it utilizes decomposition heat for refrigeration[19], an improved performance can be guaranteed [20]. Wang et al.[21] proposed a novel resorption cycle for power and refrigeration cogeneration based on resorption refrigeration. The total exergy efficiency was $0.56-0.74$, which was improved by $10 \%-40 \%$ if compared with the cogeneration performance of the Goswami cycle. However, there is less research about ammonia systems for combined refrigeration and power cogeneration based on resorption 
refrigeration.

In this paper, a novel resorption system for power generation and refrigeration cogeneration is investigated with higher refrigeration COP as well as improved safety. In order to have an overall understanding of this novel system, energy and exergy efficiency analysis is used for comparison.

\section{Establishment of the resorption cogeneration cycle}

The resorption system diagram for power and refrigeration cogeneration is presented in Fig.1a, which mainly includes oil tanks, HTS and LTS adsorption beds, turbine and other auxiliary components such as valves and pumps. Fig.1b presents thermodynamic process, in which $\mathrm{MnCl}_{2} / 6-2$ means the reaction process between $\mathrm{MnCl}_{2}$ and ammonia from 6 to 2 mole according to Equation 1. Similarly, $\mathrm{CaCl}_{2} / 8-4$ is that $\mathrm{CaCl}_{2}$ and ammonia from 8 to 4 mole as Equation 2. All the transformation process for thermal analysis is considered as ideal. The working processes are as follows:

(1) Desorption process of HTS bed. In this process, V1, V3, V2, V2 ,AV1 and AV2 are open while AV3 is close as shown in Fig.1a. HTS bed is heated by oil tank 1 inside simulating as low grade heat. The temperature of oil tank is controlled as $120-170^{\circ} \mathrm{C}$ while the outlet pressure is about $0.3 \mathrm{MPa}$. Meanwhile, LTS bed is cooled by the cooling tank which simulates as heat sink. Temperature of cooling tank is controlled as the $25-35^{\circ} \mathrm{C}$ while the outlet pressure is about $0.25 \mathrm{MPa}$. The desorbed ammonia of HTS bed through AV2 is expanded in the turbine and generates power there. The expanded ammonia will be adsorbed by LTS bed through AV1. For thermodynamic process in Fig.1b, Point A is the isothermal and isobaric desorption process of $\mathrm{MnCl}_{2} \cdot 6 \mathrm{NH}_{3}$ to $\mathrm{MnCl}_{2} \cdot 2 \mathrm{NH}_{3}$ at desorption temperature of HTS $\left(T_{\mathrm{deH}}\right)$, and A-B is the isobaric superheating process. B-C is isentropic power generation processes. Refrigeration power is able to be obtained in the precooler below refrigeration temperature $T_{\mathrm{e}}$ by the isobaric heating process (C-D) of the expanded ammonia. $T_{\mathrm{e}}$ is set according to the demand, which is generally same as refrigeration temperature in resorption process. Compared with resorption refrigeration, refrigeration of this part is negligible[21], so precooler is not designed in the system. D-E is isobaric heating processes of expanded ammonia above $T_{\mathrm{e}}$, while the isobaric and isothermal adsorption processes for ammoniate LTSs take place at E with adsorption temperature of $\operatorname{LTS}\left(T_{\text {adL }}\right)$.

(2) Desorption process of LTS bed. After the desorption process, resorption refrigeration phase 
starts as shown in Fig.1a. AV3, V5,V6, V7 and V8 are open while AV1, AV2, V1, V2, V3 and V4 close. HTS bed is cooled and adsorb ammonia from LTS bed when its pressure is lower than that of LTS bed. Desorption process of LTS bed generates the refrigeration power and transports the refrigeration power to chilled tank. Temperature of chilled tank is controlled as the -15 to $15^{\circ} \mathrm{C}$ while the outlet pressure is about $0.25 \mathrm{MPa}$. For thermodynamic process shown in Fig.1b, isobaric and isothermal refrigerating processes take place at point $\mathrm{F}$. E-F is isochoric and isosteric cooling process for $\mathrm{CaCl}_{2}$-ammonia compounds, which is controlled by chilled water tank, and ethylene glycol solution is used to exchange the heat of LTS reactor for cooling. F-G is isobaric heating processes of ammonia vapor desorbed from LTS ammonia compounds. At point $G$ the isobaric and isothermal adsorption processes of the ammoniate HTS compound at adsorption temperature of HTS $\left(T_{\mathrm{adH}}\right)$.

$$
\begin{aligned}
& \mathrm{MnCl}_{2} \cdot 2 \mathrm{NH}_{3}+4 \mathrm{NH}_{3} \leftrightarrow \mathrm{MnCl}_{2} \cdot 6 \mathrm{NH}_{3}+4 \Delta \mathrm{H}_{\mathrm{MnCl}_{2}} \\
& \mathrm{Ca} \mathrm{C}_{2} \mathrm{l} \quad \mathrm{N}_{3} \mathrm{H4} \quad \mathrm{N} \leftrightarrow \mathrm{C}_{2} \mathrm{HCCl}{ }_{3} \mathrm{HA}_{a_{C}}
\end{aligned}
$$

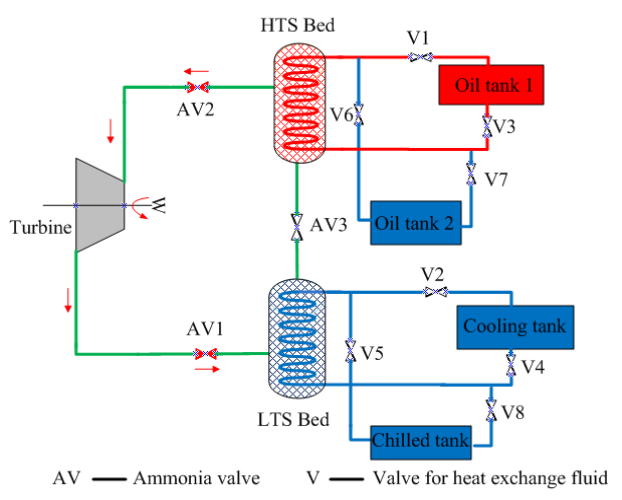

(a)

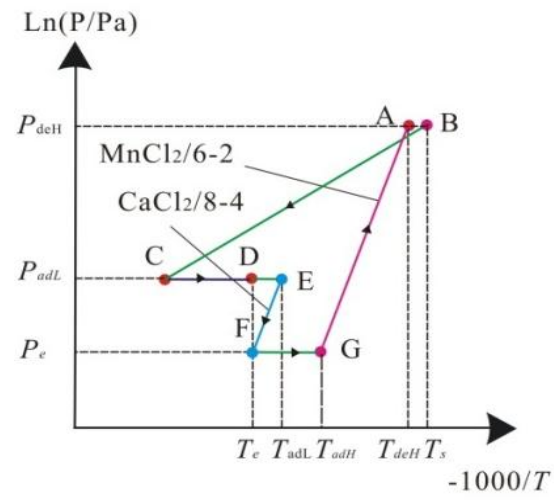

(b)

Fig.1. Resportion cycles for power and refrigeration cogeneration (a) System diagram, (b) Thermodynamic process diagram.

Fig.2a is the photo of resorption refrigeration part. Six shell-and-tube type vessels are used as two adsorption beds, i.e. HTS and LTS bed. Temperature of HTS adsorption bed is controlled by the oil tank while LTS adsorption bed is controlled by ethylene glycol aqueous solution tank. $4.8 \mathrm{~kg} \mathrm{MnCl}_{2}$ and $3.9 \mathrm{~kg} \mathrm{CaCl}_{2}$ impregnated in ENG-TSA with mass ratio of 6:1 [22]. ENG-TSA can effectively enhance the mass transfer and adsorption effectiveness due to its porous construction. PCM tanks are designed to recover the redundant heat and cooling power, but the experiment dosen't has concerned the PCM part. 
Fig.2b is the photo of cogeneration system including oil tank, cooling tower, resorption refrigeration part and power generation part. The power generation part is composed of the scroll expander (ATC-066C2, design and produced by Aotecar Company), torque meter for testing the torque and rotation rate and electricity generator (rated voltage $14 \mathrm{~V}$ and maximum current $120 \mathrm{~A}$ ). Pressure sensors (full scale from 0 to $2.5 \mathrm{MPa}$ with tolerance of $\pm 0.1 \%$ ) are placed at the inlet and outlet of the expander and in the adsorption beds. Pt100 thermal resistance temperature sensors with $0.5 \%$ accuracy are used. Structure of adsorption bed and the location of temperature sensors are shown in the Fig.3. It indicates that temperature sensor of $\mathrm{T}_{1, \mathrm{HTS}}$ is closer to the heat transfer fluid than $\mathrm{T}_{2, \mathrm{HTS}}$.

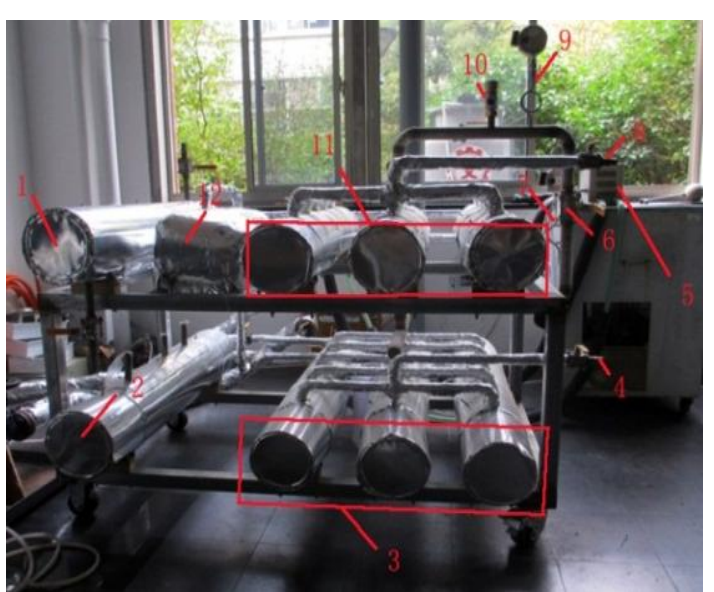

(a)

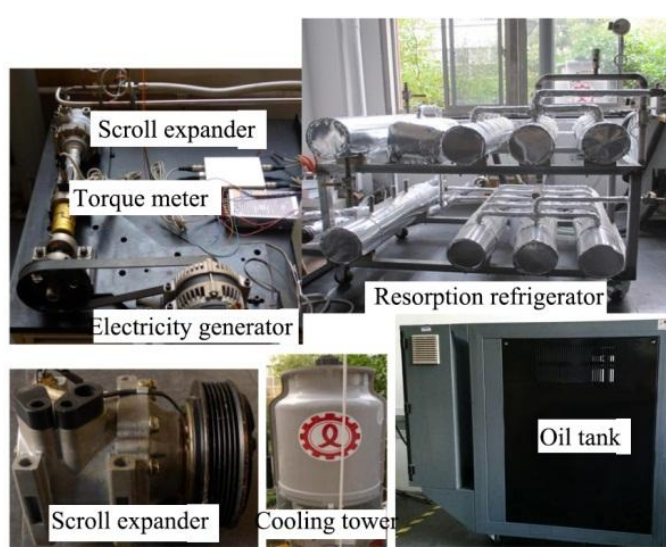

(b)

(1) Low temperature PCM energy storage tank used for redundant heat; (2) High temperature PCM energy storage tank used for redundant cooling power; (3) HTS adsorption bed; (4) Outlet ammonia valve for power generation ; (5) Ethylene glycol aqueous solutiontank; (6) Ammonia valve for resorption process;(7) Pressure sensors; (8) Inlet ammonia valve for power generation; (9) Pressure gauge; (10) Safety valve; (11)LTS adsorption bed; (12) heat exchanger for cooling the oil tank.

Fig.2. Photo of cogeneration system (a) Resorption refrigeration part, (b) Cogeneration system with auxiliary equipment

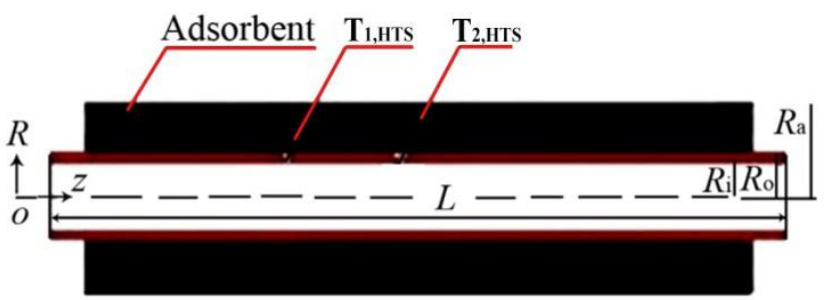

(a)

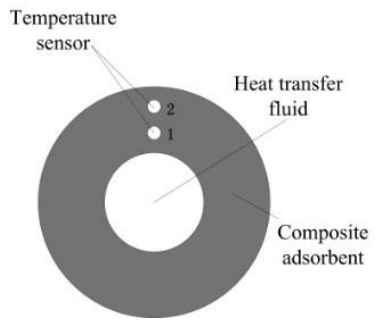

(b)

Fig.3. Unit adsorption bed, (a) Scheme of unit adsorption bed; (b) Vertical view of the reactor structure and sensors.

To have a better understanding of performance of cogeneration system and optimal operation strategies, individual test for the refrigeration performance is carried out before the cogeneration 
performance test. After that, cogeneration system is tested. Heat source temperature in the oil tank ranges from $120^{\circ} \mathrm{C}$ to $170^{\circ} \mathrm{C}$. Cooling temperature changes from $25^{\circ} \mathrm{C}$ to $35^{\circ} \mathrm{C}$ simulated as summer time. In the testing process heating time and refrigeration time is first controlled as 30 min and $15 \mathrm{~min}$, respectively. Different cycle time is investigated later.

\section{Performance evaluation}

Performance of the system is evaluated by three parameters, which are cooling capacity $Q_{\text {ref }}$, thermal coefficient of performance $(C O P)$, and specific cooling power per kilogram adsorbent (SCP). Heating power of the system is calculated by:

$$
Q_{\text {heat }}=\int_{0}^{t_{\text {heating }}} c_{o} \cdot m_{o} \cdot\left(T_{H T S, \text { in }}-T_{H T S, \text { out }}\right) d t / t
$$

where $Q_{\text {heat }}$ is the heating power provided by hot oil. $t_{\text {heating }}$ is heating time. $c_{\mathrm{o}}$ is specific heat of oil. $T_{\mathrm{HTS}, \text { in }}$ and $T_{\mathrm{HTS}, \text { out }}$ are the inlet and outlet temperature of HTS adsorption bed.

Thermal exergy is:

$$
E_{\text {heat }}=Q_{\text {heat }} \times\left(1-\frac{T_{0}}{T_{\text {res }}}\right)
$$

where $T_{0}$ is environmental temperature. $T_{\text {res }}$ is average temperature of heat fluid inlet and outlet.

Cooling capacity is:

$$
Q_{r e f}=\int_{0}^{t_{r e f}} c_{w} \cdot m_{w} \cdot\left(T_{L T S, i n}-T_{L T S, \text { out }}\right) d t / t
$$

where $t_{\text {ref }}$ is the refrigeration time. $m_{w}$ is the flowrate of ethylene glycol aqueous solution. $c_{w}$ is specific heat of ethylene glycol aqueous solution. $T_{\mathrm{LTS} \text {,in }}$ and $T_{\mathrm{LTS} \text {,out }}$ is the inlet and outlet temperature of LTS adsorption bed.

Refrigeration exergy is:

$$
E_{\text {ref }}=Q_{\text {ref }} \cdot\left(\frac{T_{0}}{T_{\text {chill,ave }}}-1\right)
$$

where $T_{\text {chill,ave }}$ is average temperature of chilled water.

Ideal coefficient of performance $\left(C O P_{\text {ideal }}\right)$ and coefficient of performance $(C O P)$ is:

$$
C O P_{\text {ideal }}=\frac{\Delta H_{r, \mathrm{LTS}}}{\Delta H_{r, \mathrm{HTS}}} \quad C O P=\frac{Q_{r e f}}{Q_{\text {heat }}}
$$

where $\Delta H_{\mathrm{r}, \mathrm{LTS}}$ is the enthalpy of LTS adsorbent. $\Delta Q_{\mathrm{r}, \mathrm{HTS}}$ is the enthalpy of HTS adsorbent. $Q_{\text {ref }}$ is 
cooling capacity. $Q_{\text {heat }}$ is heating power.

Specific cooling power per kilogram adsorbent can be expressed as:

$$
S C P=\frac{Q_{r e f}}{t_{\text {cycle }} \cdot m_{t o t}}
$$

where $m_{\mathrm{tot}}$ is total mass of composite adsorbent. $t$ is cycle time.

Total energy efficiency and exergy efficiency:

$$
\eta_{\text {to.t } e \bar{n}} \frac{Q_{\text {reff }}+W}{Q_{\text {he at }}} \quad \eta_{\text {total }, e x}=\frac{E_{\text {ref }}+W}{E_{\text {heat }}}
$$

\section{Results and discussions}

\section{1 Temperature and pressure}

In the heating process, temperature and pressure variation of adsorbent under different heat source temperature show the similar trends, which is shown in Fig. 4 with $160^{\circ} \mathrm{C}$ heat source temperature. Fig.4a shows temperature variation of the adsorbent with different radius; Fig.4b shows the pressure of two adsorption beds. Heating process can be divided into several phases. In the first 0-15 minutes, temperature of HTS adsorbent increases gradually, and heating power is mainly consumed by sensible heat of adsorbent and metal of adsorption bed. Since HTS and LTS bed are mutually connected, pressure of adsorption bed is namely system pressure. In this phase, temperature and pressure of LTS adsorbent basically keeps constant. As Fig. 3 shows, $T_{1, \mathrm{HTS}}$ is located closer to the heat transfer fluid than $T_{2, \mathrm{HTS}}$. Since heat transfer resistance exists along the direction of heat transfer of heating fluid, $T_{1, \mathrm{HTS}}$ is higher than $T_{2, \mathrm{HTS}}$ in the heating process. Temperature of cooling water $T_{\text {cool }}$ keep constant since no chemical reaction happens. After that in 15-30 minutes, when LTS adsorbent is heated to $100-110^{\circ} \mathrm{C}$, system pressure increases sharply from $0.1 \mathrm{MPa}$ to $0.7 \mathrm{MPa}$. The increment of system pressure indicates desorption happens in the HTS bed, and desorption heat accounts for part of heating power, and proportion of sensible heat of metal decreases causing temperature of HTS adsorbent increase slowly. Simultaneously, adsorption process happens in LTS adsorption bed, and temperature of LTS adsorbent increases sharply due to large adsorption heat between $\mathrm{CaCl}_{2}$ and ammonia, which takes the similar trends as but higher than cooling water temperature. Cooling water temperature $T_{\text {cool }}$ increases $4^{\circ} \mathrm{C}$ in this process. For the last 30-42 minutes, temperature of HTS adsorbent increases sharply again. Temperature of cooling water $T_{\text {cool }}$ restores to be constant. Heating power is mainly consumed by sensible heat of metal of HTS bed and adsorbent, which means heating process has been 
finished.

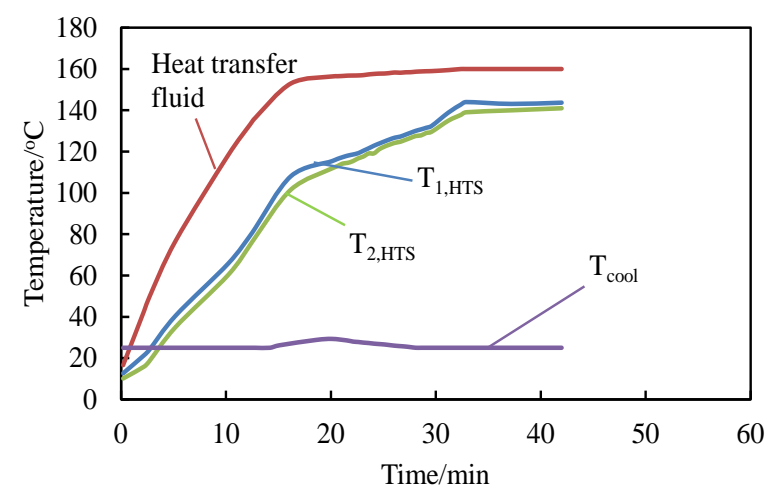

(a)

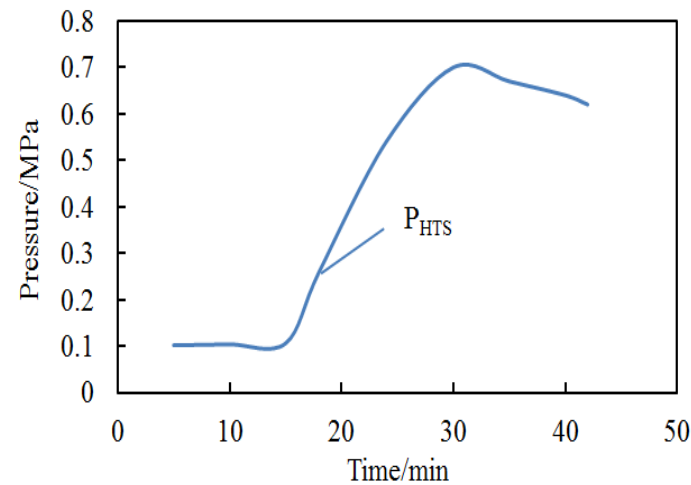

(b)

Fig.4. Variation of temperature and pressure in high period phase with the heat source temperature $160^{\circ} \mathrm{C}$ (a) Temperature, (b) Pressure.

\subsection{Instantaneous cooling power}

Fig.5 shows the instantaneous cooling power under both air conditioning condition and freezing condition with $160{ }^{\circ} \mathrm{C}$ heat source temperature and $25{ }^{\circ} \mathrm{C}$ cooling temperature. Instantaneous cooling power of the system can be obtained by calculating the inlet and outlet temperature difference of LTS reactor through Equation 5. Results show that instantaneous cooling power increases rapidly at the beginning of 5-10min. Under air conditioning condition, chemical reaction proceeds fast due to the larger reaction driven force between the evaporation temperature and reaction temperature of LTS. For $15^{\circ} \mathrm{C}$ refrigeration temperature the highest instantaneous cooling power can reach $4.089 \mathrm{~kW}$, which maintains $1-2 \mathrm{~min}$ within $5 \%$ of the highest value. Under freezing condition, instantaneous cooling power tends to be relatively smaller due to the lower evaporation temperature and reaction temperature of LTS. Compared with air conditioning condition, the highest cooling power of system can reach $1.158 \mathrm{~kW}$, which maintains $5-6 \min$ for $-5^{\circ} \mathrm{C}$ freezing temperature within $10 \%$ of the highest value. For further analysis, air conditioning condition leads to rapid change of cooling power while freezing condition doesn't. This is mainly because desorption rate of LTS adsorbent is larger than adsorption rate of HTS adsorbent. When the ammonia valve is open HTS adsorbent cannot adsorb the refrigerant 
immediately, which causes the pressure increment of the system. Comparably, desorption rate of LTS adsorbent is relatively small, which can match adsorption rate of HTS adsorbent, and it causes the cooling power change smoothly under the freezing condition.

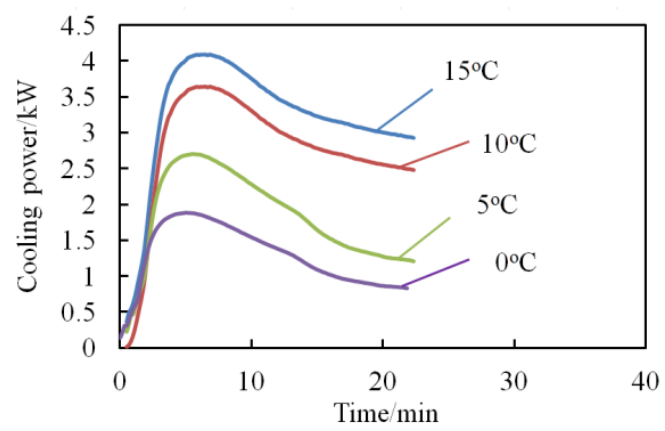

(a)

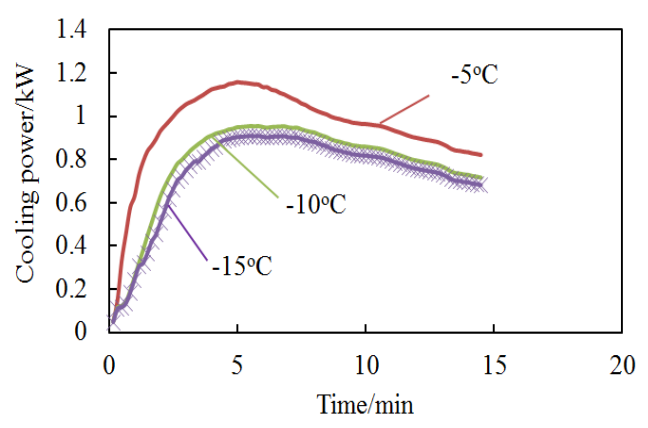

(b)

Fig. 5. The instantaneous cooling power ( a ) Air conditioning condition, ( b ) Freezing condition.

\subsection{Refrigeration performance with different heat source temperature}

For $\mathrm{MnCl}_{2}-\mathrm{CaCl}_{2}-\mathrm{NH}_{3}$ resorption cogeneration system, theoretical $C O P_{\text {ideal }}$ of system could reach 0.68 through Equation 5. By analyzing the metal heat capacity ratio between adsorption bed and adsorbent, sensible heat account for $38-42 \%$ of the whole system heat input. For this metal capacity ratio, the maximum $C O P_{\text {ideal }}$ of the resorption system is about 0.39-0.42. Fig.6 shows refrigeration performance of the system under different heat source temperature. Since different refrigeration temperature show similar trend along with heat source temperature, $10^{\circ} \mathrm{C}$ and $15^{\circ} \mathrm{C}$ refrigeration temperature are chosen as the example. Fig.6a and Fig.6b indicate $C O P$ and $S C P$ of the system change with heat source temperature. Results show that $160^{\circ} \mathrm{C}$ heat source temperature is an inflection point. When heat temperature is higher than $160^{\circ} \mathrm{C}$, sensible load of the system increases, which means keeping heating HTS adsorption bed is not able to improve the system performance. For refrigeration temperature of $15^{\circ} \mathrm{C}$ and $10^{\circ} \mathrm{C}, C O P$ of the system ranges from 0.284 to 0.396 and 0.277 to 0.368 , respectively. For heat source temperature of $120^{\circ} \mathrm{C}, \mathrm{COP}$ of $15^{\circ} \mathrm{C}$ refrigeration temperature is close to that of $10^{\circ} \mathrm{C}$. That is mainly because ammonia conversion rate is not enough to discriminate the effect of heat source on refrigeration performance under relative low heat source temperature. $S C P$ of the system ranges from 39.4 to $136 \mathrm{~W} / \mathrm{kg}$ and 36.8 to $128.4 \mathrm{~W} / \mathrm{kg}$, respectively, for refrigeration temperature of $15^{\circ} \mathrm{C}$ and $10^{\circ} \mathrm{C}$. SCP also increases with heat source temperature. 


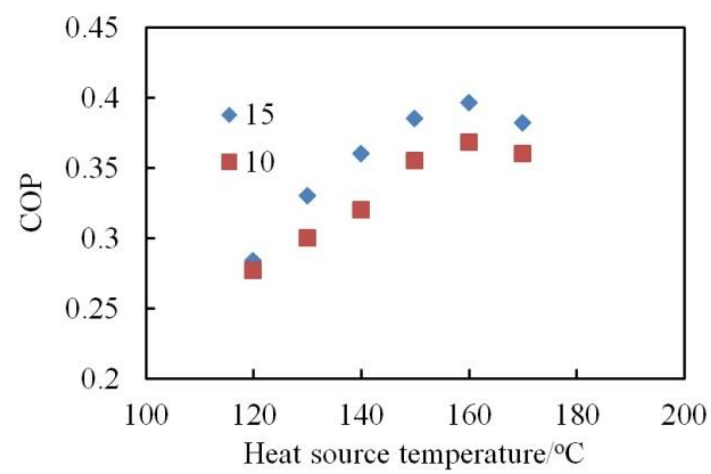

(a)

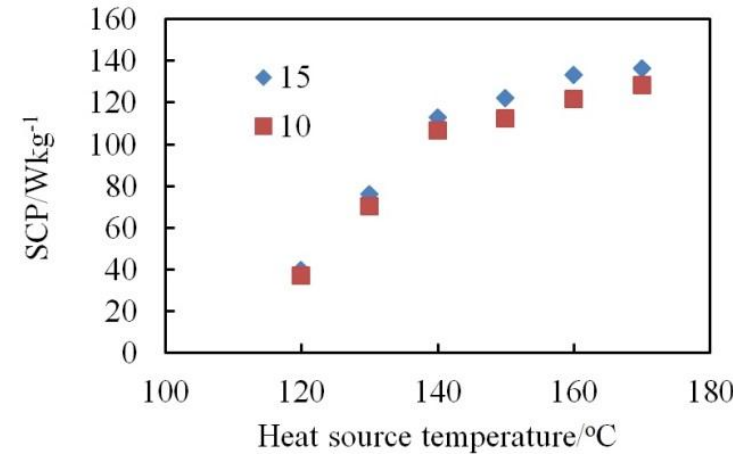

(b)

Fig.6. Refrigeration Performance of resorption system under different heat source temperature (a) $C O P$, (b) $S C P$.

\subsection{Refrigeration performance with different cycle time}

Cycle time of the resorption system can be divided into two parts. One is the desorption time of HTS beds $\left(t_{\text {des }}\right)$, i.e. desorption time of $\mathrm{MnCl}_{2}$ adsorbent or adsorption time of $\mathrm{CaCl}_{2}$. The other is refrigeration time of LTS bed $\left(t_{a \mathrm{ds}}\right)$, i.e. desorption time of $\mathrm{CaCl}_{2}$ adsorbent or adsorption time of $\mathrm{MnCl}_{2}$. Cycle time of the system is composed of two parts: adsorption and desorption of $\mathrm{MnCl}_{2}$ adsorbent, i.e. $t_{\mathrm{cyc}}=t_{\mathrm{ads}}+t_{\mathrm{des}}$. Experiment shows that $\mathrm{MnCl}_{2}$ needs sufficient ammonia to produce good refrigeration effect, and adsorption time of $\mathrm{MnCl}_{2}\left(t_{a \mathrm{ds}}\right)$ is set as $15 \mathrm{~min}$ [23]. Under this adsorption time, the optimal desorption time between $\mathrm{MnCl}_{2}$ and $\mathrm{CaCl}_{2}$ is investigated and compared by evaluation of $S C P$ and $C O P$ with $160^{\circ} \mathrm{C}$ regeneration temperature, $25^{\circ} \mathrm{C}$ cooling temperature, and $10{ }^{\circ} \mathrm{C}$ evaporating temperature. As Fig.7 shows, desorption time of $\mathrm{MnCl}_{2}$ varies from 16 to $28 \mathrm{~min}$, and the time gradient is $3 \mathrm{~min}$. It is indicated that both $C O P$ and $S C P$ increase first then decrease with the increment of desorption time of HTS adsorbent. The highest SCP and COP are obtained as $113.3 \mathrm{~W} / \mathrm{kg}$ and 0.364 for desorption time of 22 and $25 \mathrm{~min}$. For different adsorption/desorption time, SCP and COP range from 65.6 to $113.3 \mathrm{~W} / \mathrm{kg}$ and 0.13 to 0.364 , respectively. It indicates that the optimal desorption time $t_{\text {des }}$ should be longer than the adsorption time of $\mathrm{MnCl}_{2} t_{a d s}$. This is mainly because of the larger heat capacity ratio between metal of HTS adsorption bed and adsorbent. Since metal capacity of the system 
accounts for $38 \%-42 \%$ of total heat input, metal parts of the system take several minutes for heating in the desorption process. According to thermodynamic analysis of $\mathrm{MnCl}_{2}-\mathrm{CaCl}_{2}-\mathrm{NH}_{3}$, adsorption kinetics is related with the driving temperature lift, which is the difference between adsorbent temperature and equilibrium adsorption/desorption temperature. The larger driven temperature difference is, the higher adsorption and desorption rate becomes. Therefore, desorption time $t_{\text {des }}$ of $\mathrm{MnCl}_{2}$ ought to be longer than adsorption time $t_{\mathrm{ads}}$ of $\mathrm{MnCl}_{2}$, which can desorb ammonia to $\mathrm{CaCl}_{2}$ completely, thus producing the better refrigeration effect.

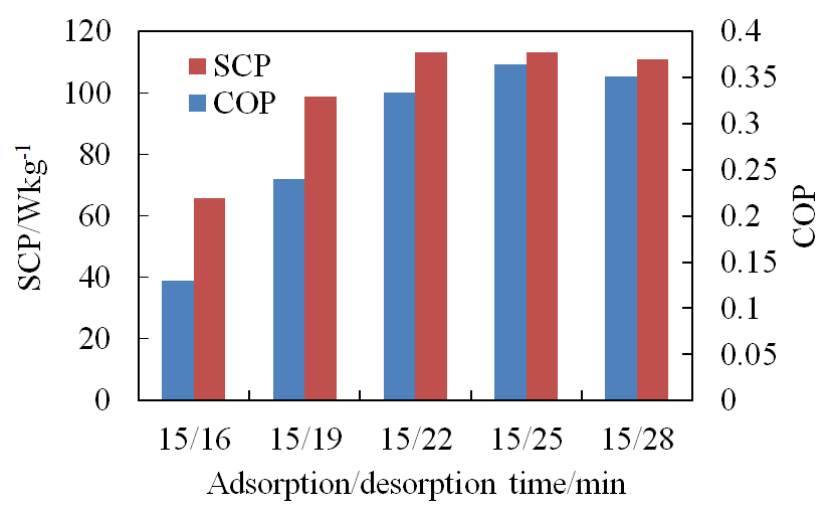

Fig.7. The effect of ratio of adsorption /desorption time on the system SCP and COP.

Considering about that the optimal desorption time should be longer than adsorption time of $\mathrm{MnCl}_{2}$, several sets of the cycle time with shorter adsorption time of $\mathrm{MnCl}_{2}$ and longer desorption time (Table 1) are planned for the experiments, for which adsorption time of $\mathrm{MnCl}_{2}$ generally $1 / 3$ to $1 / 4$ less than desorption time, similarly with the ratio between the optimal adsorption time for $\mathrm{MnCl}_{2}$ and the desorption time. $S C P$ and $C O P$ are analyzed for different cycle time as shown in Table 1, and in the experiments the heat source temperature, cooling temperature and refrigerating temperature are chosen as $160^{\circ} \mathrm{C}, 25^{\circ} \mathrm{C}$ and $10^{\circ} \mathrm{C}$, respectively. Fig. 8 shows that $S C P$ and $C O P$ change with cycle time, which is the sum of adsorption and desorption time of $\mathrm{MnCl}_{2}$. Cycle time ranges from 20 to $60 \mathrm{~min}$. 5 minutes is considered as time gradient from 20 to 40 min since adsorption performance changes severely. 10 minutes is considered as time gradient in the 40 to 60 min since adsorption performance changes more 
slightly. It can be seen that $S C P$ and $C O P$ increase fast with cycle time from 20 to $35 \mathrm{~min}$. For cycle time from 35 to $60 \mathrm{~min}, S C P$ increases first then decreases fast while $C O P$ increases and decreases gradually. Comparably, COP changes slightly in this period.

Table $1 \mathrm{MnCl}_{2}$ adsorption /desorption time in different cycle time

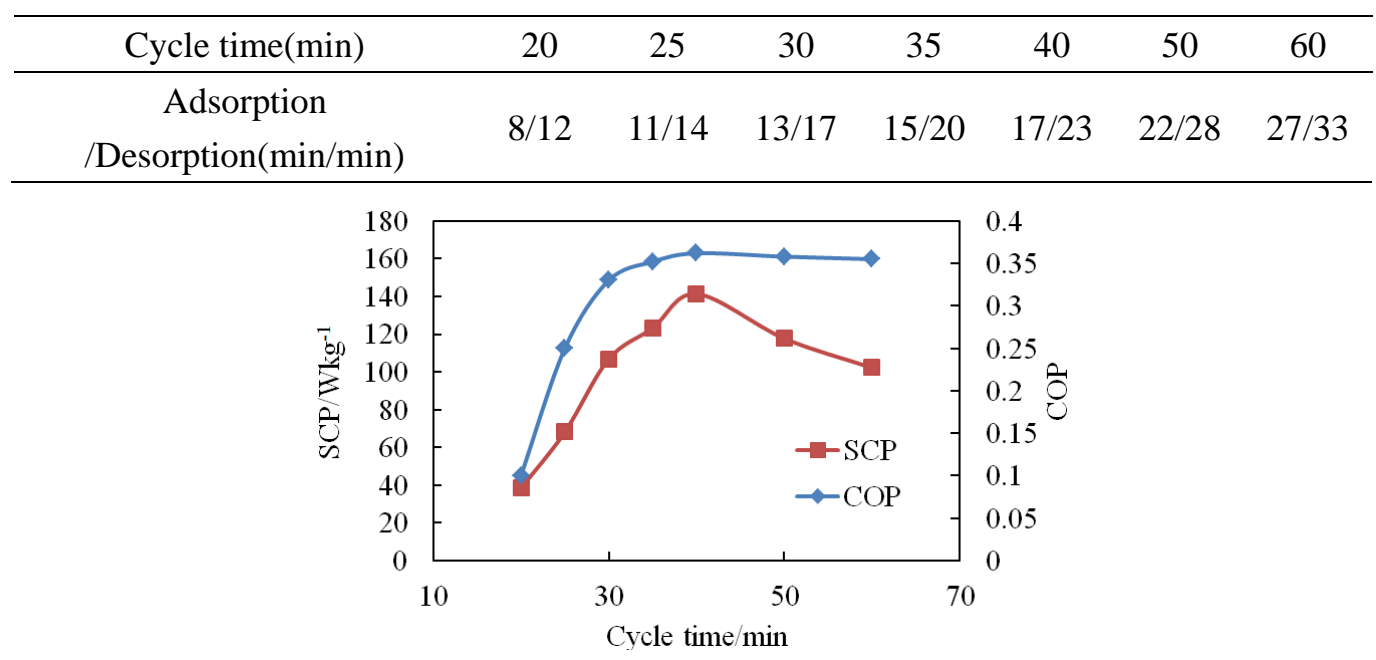

Fig. 8. SCP and COP change with cycle time under the condition $\left(160^{\circ} \mathrm{C}, 25^{\circ} \mathrm{C}, 10^{\circ} \mathrm{C}\right)$.

\section{5 Power generation}

For power generation process, scroll expander severely hinders the decomposition reaction, because pressure difference is fully originated from the driving force of the decomposition. The smaller pressure difference is, the slower desorption rate becomes, leading to unstable rotating movement of the expander or it could be even worse when the expander stops running. According to refrigeration performance of resorption part, $160^{\circ} \mathrm{C}$ is optimal heat source temperature, and desorption process happens from 15 to 30min. Therefore, power generation performance is studied according to different desorption time under $160^{\circ} \mathrm{C}$ heat source temperature and $25^{\circ} \mathrm{C}$ cooling temperature condition. The method that has been tried in the experiment is holding on the flow for 2-3mins when expander stops rotating, and then open the ammonia valve for power generation again. Such a process renders the flow rate behaving like some pulses. Fig.9 shows average shaft power and heat when ammonia valve opens at different desorption time of HTS. Heat is calculated by multiplying the average shaft power and time lasted for power generation, which is able to refer to the Equation 10. Results shows that when desorption time varies from 20 to $30 \mathrm{~min}$, average shaft power output of the cogeneration system increases from $45.8 \mathrm{~W}$ to $103.7 \mathrm{~W}$ while heat output increases from $5.5 \mathrm{~kJ}$ to $11.1 \mathrm{~kJ}$, then decreases to 
7.3kJ. For the average shaft power keeps increasing with the desorption time of opening valve. However, average shaft power cannot be reflected the total quantity output. For instance, expander is driven for generating power once when ammonia valve opens at $27^{\text {th }}$ minute of desorption time. After generating power once, the residue ammonia cannot drive the expander for generating power for the second time. When opening ammonia valve ahead $27^{\text {th }}$ minute of desorption time, the residue ammonia can drive expander for extra power. When over $27^{\text {th }}$ minute of desorption time, the residue ammonia cannot drive expander again. Therefore, heat is utilized to describe the total quantity for the power generation process. Considering the performance of refrigeration and power, $25^{\text {th }}$ min desorption time is selected as the optimal time to open the ammonia valve.

$$
\text { Heat }=P_{1 a v e} \cdot t_{1}+P_{2 a v e} \cdot t_{2}=P_{a v e} \cdot t
$$

where $P_{1 \text { ave }}$ is the average shaft power for the first power generation. $t_{1}$ is time of first power generation. $P_{2 \text { ave }}$ is the average shaft power for the second power generation. $t_{2}$ is time of first power generation. $P_{\text {ave }}$ is the average shaft power. $t$ is the sum of $t_{1 \text { ave }}$ and $t_{2 \text { ave }}$.

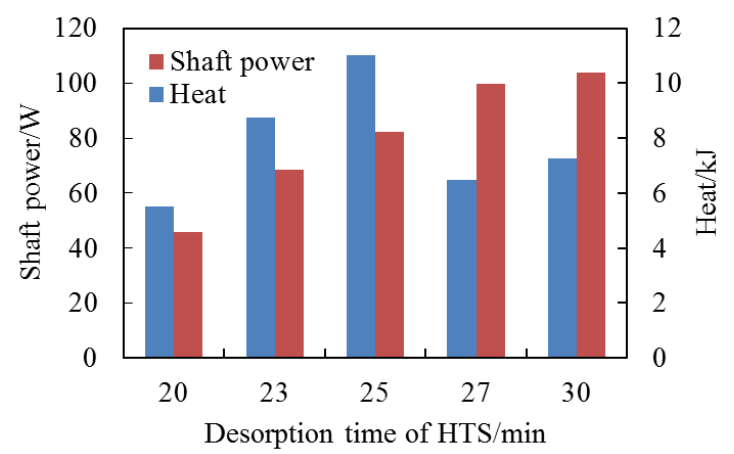

Fig. 9. Average shaft power and heat for different desorption time of HTS.

Fig.10 shows power generation performance. Two segmental power generation processes last for 64 and 50s, respectively. The maximum power output is nearly $253 \mathrm{~W}$ and average value is $82.3 \mathrm{~W}$. Compared with refrigeration power, the electrical power is very low. The main reason is because scroll expander is refitted from scroll compressor. One system flaw existing from the very beginning is the capability mismatch between the adsorption unit and scroll expander which is not customized for this test specification. However, this expander is the smallest type available during the selection scope. The 
highest temperature of the cooling water outlet is about $4^{\circ} \mathrm{C}$ higher than the inlet, which is lower than that without the scroll expander. This is mainly because the residue ammonia in the pipe and chamber of the scroll expander is not adsorbed by the LTS adsorption bed. Fig.11 indicates power generation performance with different heat source temperature. Results show that average shaft power of the system increases with the increment of heat source temperature. When heat source temperature is $180^{\circ} \mathrm{C}$, average shaft power output reaches $105.2 \mathrm{~W}$. For different heat source temperature, average shaft power output ranges from 62.1 to $105.2 \mathrm{~W}$.

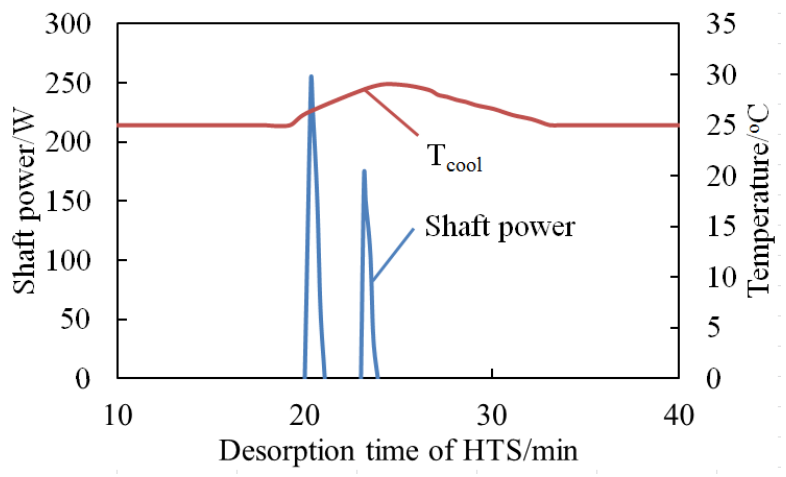

Fig. 10. Power generation performance.

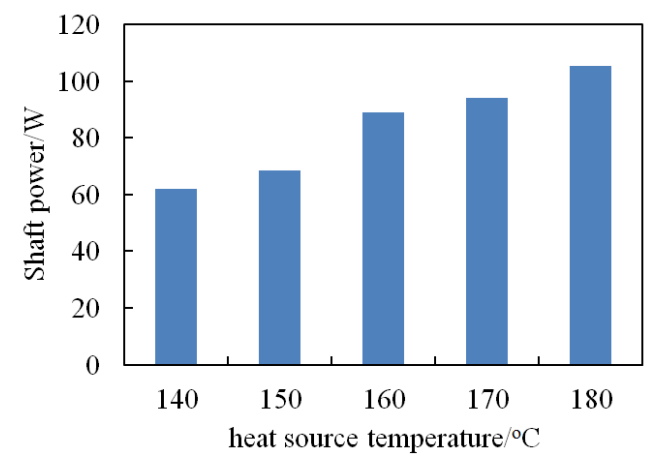

Fig. 11. Power generation performance for different heat source temperature.

\subsection{Analysis of cogeneration performance}

Fig.12 shows refrigeration temperature variation of the cogeneration system with and without the expander. By analyzing the refrigeration temperature for $10^{\circ} \mathrm{C}, 0^{\circ} \mathrm{C}$ and $-10^{\circ} \mathrm{C}$, refrigeration performance of the cogeneration system do have the difference with resorption refrigeration individually. When the chilled water inlet is $10^{\circ} \mathrm{C}$, temperature decline of the cogeneration system is 
smaller than that of resorption refrigeration individually, and the largest gap can reach $0.95^{\circ} \mathrm{C}$. This is mainly because the residue of ammonia in the chamber of scroll expander and pipe in the desorption process of power generation. When scroll expander cannot expand for the work output due to lower pressure difference and small flowrate, the residue ammonia won't be adsorbed by the LTS adsorption bed, which leads to the loss of adsorption quantity in the refrigeration process of LTS adsorbent. The temperature difference caused by the scroll expander becomes smaller gradually with decrease of chilled water temperature. When temperature of chilled water inlet is $-10^{\circ} \mathrm{C}$, performance of cogeneration system is close to the resorption refrigeration process. This is mainly because ammonia desorbed by the LTS adsorbent is relatively limitable when the refrigeration temperature is low. Under air conditioning condition, bypass can be utilized for scroll expander for recovering the residue cooling power, i.e. when pressure between HTS adsorption bed and LTS adsorption bed is not enough to drive the scroll expander for work, open the bypass and the residue of ammonia will be desorbed to the LTS adsorption bed for adsorption. For refrigeration temperature lower than $5^{\circ} \mathrm{C}$, there is little significance for improving the system refrigeration since the loss of residue cooling power is very small. Fig.13 shows energy efficiency and exergy efficiency vary with heat source temperature under the condition of $25^{\circ} \mathrm{C}$ cooling temperature and $10^{\circ} \mathrm{C}$ refrigeration temperature. It indicates that the total energy efficiency increases from 0.293 to 0.417 then decreases to 0.407 and exergy efficiency increases from 0.12 to 0.16 . Since the electrical power is relatively low when compared with the cooling power. Therefore, the total energy efficiency takes the same trends as the refrigeration performance. The highest electricity and refrigeration power are $253 \mathrm{~W}$ and $2.98 \mathrm{~kW}$ when heat source temperature is $160^{\circ} \mathrm{C}$ 


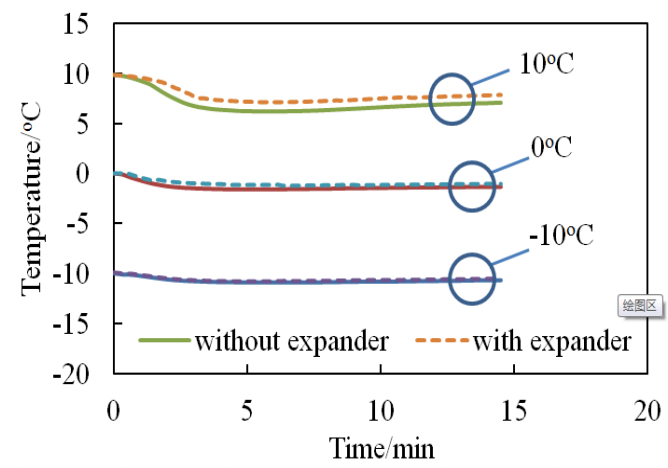

Fig.12. Refrigeration temperature variation of system with and without the expander.

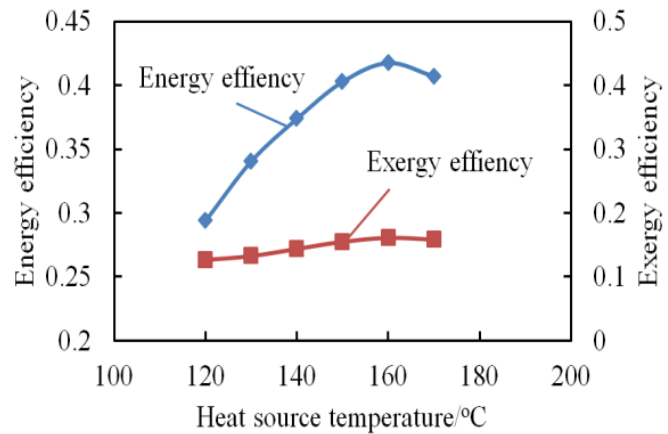

Fig.13. Energy and exergy efficiency of the cogeneration system vs. heat source temperature.

\section{Conclusions}

A novel $\mathrm{MnCl}_{2}-\mathrm{CaCl}_{2}-\mathrm{NH}_{3}$ resorption system for power and refrigeration cogeneration was presented and investigated. Individual test of the main part was carried out before the cogeneration test. Refrigeration performance of the resorption part was investigated under different heat source temperature, cooling temperature, and evaporation temperature. Later, cogeneration system was tested for comparison. Conclusions were yielded as follows:

(1) Ideal COP of the resorption system is about 0.68. Ideal COP of resorption system is about 0.42-0.45 when considering metal ratio between adsorption bed and adsorbent. $C O P$ and $S C P$ of the system change with heat source temperature. When heat temperature is higher than $160^{\circ} \mathrm{C}$, sensible load of the system increases, which means keep heating HTS adsorption bed is not able to improve the system performance. For refrigeration temperature of $15^{\circ} \mathrm{C}$ and $10^{\circ} \mathrm{C}$, COP of the system ranges from 0.284 to 0.396 and 0.277 to 0.368 , respectively. SCP of the system ranges from 39.4 to $136 \mathrm{~W} / \mathrm{kg}$ and 36.8 to $128.4 \mathrm{~W} / \mathrm{kg}$, respectively. 
(2) Instantaneous cooling power increases remarkably in the first $5-10 \mathrm{~min}$. For $15^{\circ} \mathrm{C}$ refrigeration temperature the highest instantaneous cooling power can reach $4.089 \mathrm{~kW}$, which maintains 1-2min within $5 \%$ of the highest value. Compared with air conditioning condition, the highest cooling power of system can reach $1.158 \mathrm{~kW}$, which maintains $5-6 \mathrm{~min}$ for $-5^{\circ} \mathrm{C}$ freezing temperature within $10 \%$ of the highest value.

(3) When the chilled water inlet is $10^{\circ} \mathrm{C}$, temperature decline of the cogeneration process is smaller than that of resorption refrigeration process, and the largest gap can reach $0.95^{\circ} \mathrm{C}$. When temperature of chilled water inlet is $-10^{\circ} \mathrm{C}$, performance of cogeneration system is very close to the resorption refrigeration system individually.

(4) For the power generation processes two segmental power generations lasted for 64 and 50s are achieved. The maximum power output is nearly $253 \mathrm{~W}$ and overall average value is $82.3 \mathrm{~W}$ last for $114 \mathrm{~s}$. The total energy efficiency increases from 0.293 to 0.417 then decrease to 0.407 and exergy efficiency increases from 0.12 to 0.16 . The highest power and refrigeration power are $253 \mathrm{~W}$ and $2.98 \mathrm{~kW}$ when the heat source temperature is $160^{\circ} \mathrm{C}$.

\section{Acknowledgements:}

This research was supported by the National Science Foundation of China for Excellent Young Scholars under contract number 51222601, the Foundation for Innovative Research Groups of the National Natural Science Foundation of China under contract number 51521004.

\section{References}

[1] Goyal P, Baredar P, Mittal A, Siddiqui AR. Adsorption refrigeration technology - An overview of theory and its solar energy applications. Renewable and Sustainable Energy Reviews. 2016;53:1389-410. 
[2] Yari M, Mehr AS, Zare V, Mahmoudi SMS, Rosen MA. Exergoeconomic comparison of TLC (trilateral Rankine cycle), ORC (organic Rankine cycle) and Kalina cycle using a low grade heat source. Energy. 2015;83:712-22.

[3] Muratori M, Schuelke-Leech B-A, Rizzoni G. Role of residential demand response in modern electricity markets. Renewable and Sustainable Energy Reviews. 2014;33(0):546-53.

[4] Kalina AI. Combined cycle and waste-heat recovery power systems based on a novel thermodynamic energy cycle utilising low temperature heat for power generation. . ASME Paper. 1983;83:83-JPGC-GT-3.

[5] Corman J. Gas turbine combined cycle. Conference Gas turbine combined cycle, Morgantown, West Virginia. p. 17-9.

[6] Vélez F, Segovia JJ, Martín MC, Antolín G, Chejne F, Quijano A. A technical, economical and market review of organic Rankine cycles for the conversion of low-grade heat for power generation. Renewable and Sustainable Energy Reviews. 2012;16(6):4175-89.

[7] Wang H, Peterson R, Herron T. Design study of configurations on system COP for a combined ORC (organic Rankine cycle) and VCC (vapor compression cycle). Energy. 2011;36(8):4809-20.

[8] Mohanty B, Paloso Jr G. Economic power generation from low-temperature geothermal resources using organic rankine cycle combined with vapour absorption chiller. Heat Recovery Systems and CHP. 1992;12(2):143-58.

[9] Wang L, Roskilly A, Wang R. Solar powered cascading cogeneration cycle with ORC and adsorption technology for electricity and refrigeration. Heat Transfer Engineering 2014;35:11-20. 
[10] Jiang L, Wang L, Wang R, Gao P, Song F. Investigation on cascading cogeneration system of ORC (Organic Rankine Cycle) and $\mathrm{CaCl} 2 / \mathrm{BaCl} 2$ two-stage adsorption freezer. Energy. 2014;71(0):377-87.

[11] Goswami D. Solar thermal power-status and future directions. Conference Solar thermal power-status and future directions, Suratkal, India. p. 57-60.

[12] Tamm G, Goswami DY, Lu S, Hasan AA. Theoretical and experimental investigation of an ammonia-water power and refrigeration thermodynamic cycle. Solar Energy. 2004;76(1-3):217-28.

[13] Li TX, Wang RZ, Yan T, Ishugah TF. Integrated energy storage and energy upgrade, combined cooling and heating supply, and waste heat recovery with solid-gas thermochemical sorption heat transformer. International Journal of Heat and Mass Transfer. 2014;76(0):237-46.

[14] Luo HL, Wang RZ, Dai YJ, Wu JY, Shen JM, Zhang BB. An efficient solar-powered adsorption chiller and its application in low-temperature grain storage. Solar Energy. 2007;81(5):607-13.

[15] Luo HL, Dai YJ, Wang RZ, Wu JY, Xu YX, Shen JM. Experimental investigation of a solar adsorption chiller used for grain depot cooling. Applied Thermal Engineering. 2006;26(11-12):1218-25.

[16] Bao H, Wang Y, Charalambous C, Lu Z, Wang L, Wang R, et al. Chemisorption cooling and electric power cogeneration system driven by low grade heat. Energy. 2014;72(0):590-8.

[17] Bao H, Wang Y, Roskilly AP. Modelling of a chemisorption refrigeration and power cogeneration system. Applied Energy. 2014;119(0):351-62.

[18] Wang LW, Bao HS, Wang RZ. A comparison of the performances of adsorption and resorption 
refrigeration systems powered by the low grade heat. Renewable Energy. 2009;34(11):2373-9.

[19] Goetz V, Spinner B, Lepinasse E. A solid-gas thermochemical cooling system using BaCl2 and $\mathrm{NiCl}_{2}$. Energy. 1997;22(1):49-58.

[20] Powell J, Salzano F, Yu W, Milau J. A high-efficiency power cycle in which hydrogen is compressed by absorption in metal hydrides. Science. 1976;193:314-7.

[21] Wang L, Ziegler F, Roskilly AP, Wang R, Wang Y. A resorption cycle for the cogeneration of electricity and refrigeration. Applied Energy. 2013;106(0):56-64.

[22] Wang LW, Metcalf SJ, Critoph RE, Thorpe R, Tamainot-Telto Z. Development of thermal conductive consolidated activated carbon for adsorption refrigeration. Carbon. 2012;50(3):977-86.

[23] Bao HS, Wang RZ, Wang LW. A resorption refrigerator driven by low grade thermal energy. Energy Conversion and Management. 2011;52(6):2339-44.

\section{Figure Captions}

Fig.1. Cogeneration cycles for power and refrigeration (a) System diagram, (b) Thermodynamic process diagram.

Fig.2. Photo of cogeneration system (a) Resorption refrigeration part, (b) Cogeneration system with auxiliary equipment.

Fig.3. Unit adsorption bed, (a) Scheme of unit adsorption bed; (b) Vertical view of the reactor structure and sensors.

Fig.4. Variation of temperature and pressure in high period phase with the heat source temperature $160^{\circ} \mathrm{C}(\mathrm{a})$ Temperature, (b) Pressure. 
Fig.5. Refrigeration Performance of resorption system under different heat source temperature (a) $C O P$,

(b) $S C P$.

Fig.6. The instantaneous cooling power (a)Air conditioning condition,(b)Freezing condition.

Fig.7. The effect of ratio of adsorption /desorption time on the system SCP and COP.

Fig.8. SCP and COP change with cycle time under the condition $\left(160^{\circ} \mathrm{C}, 25^{\circ} \mathrm{C}, 10^{\circ} \mathrm{C}\right)$.

Fig.9. Average shaft power for different desorption time of HTS.

Fig.10. Power generation performance of the resorption cogeneration system.

Fig. 11. Power generation performance for different heat source temperature.

Fig.12. Refrigeration temperature variation of system with and without the expander.

Fig.13. Energy and exergy efficiency of the resorption cogeneration system vs. heat source temperature. 